\title{
English Translation Teaching Model of Flipped Classroom Based on the Fusion Algorithm of Network Communication and Artificial Intelligence
}

\author{
Lei Li (i) \\ Foreign Language Department, Henan University of Chinese Medicine, Zhengzhou, 450046 Henan, China \\ Correspondence should be addressed to Lei Li; zelda_2002cn@163.com
}

Received 5 August 2021; Revised 18 September 2021; Accepted 29 September 2021; Published 31 October 2021

Academic Editor: Zhihan Lv

Copyright (c) 2021 Lei Li. This is an open access article distributed under the Creative Commons Attribution License, which permits unrestricted use, distribution, and reproduction in any medium, provided the original work is properly cited.

\begin{abstract}
With the advent of the information age and the rapid development of communication technology, traditional teaching methods and methods can no longer meet people's needs for education in the information age. This research mainly discusses the flipped classroom English translation teaching model based on the fusion algorithm of network communication and artificial intelligence. This research proposes an Internet learning platform based on Tencent's QQ communication software and mobile terminals. This learning platform can meet the learning needs of flipped classrooms, without spending a lot of investment in hardware and software development. This is a relatively ideal Internet learning platform suitable for students to carry out flipped classroom learning. Most of these mobile terminals have functions such as video playback, document reading and editing, wireless network connection, QQ communication, and large-capacity storage. These functions provide support for the smooth implementation of flip class. The video playback function can meet the needs of students to download and watch microvideos. Students can use mobile terminals to watch anytime, anywhere. The document reading and editing function can help students read related learning materials online, including self-study test questions, task lists, and teaching evaluation forms. Under this platform, students and teachers who are participants in the learning process are linked to each other through the QQ of the network terminal. The learning resources are uploaded by the teacher to the group file for students to download and watch. Students use the QQ group to give feedback and discuss difficult problems. This kind of learning network that flexibly chooses the learning time and place according to the individual student's own situation is very efficient and convenient. After the English translation test, the failure rate of the experimental class was only 3.3\%, while in the control class, the failure rate was $8.3 \%$. This research will better integrate the flipped classroom teaching mode and English translation teaching by building a learning exchange platform, which will help improve the quality of teaching.
\end{abstract}

\section{Introduction}

In the information age, the widespread application of Internet and other network technologies has caused tremendous changes in the way of teaching and learning. Various new teaching methods using microclasses, microvideos, and MOOCs as the media are gradually taking shape, and new learning methods such as personalized learning, mobile learning, and flipped learning are gradually becoming popular. As the main place for imparting knowledge and skills and cultivating quality talents, schools must comply with the requirements of educational informationization.
In order to make the innovation of classroom teaching meet the needs of the times, many new teaching methods and concepts have been born under the new curriculum reform. The passive learning method of students in class and homework provides a new choice for teaching reform.

The decrease of student satisfaction and motivation in the flipped classroom teaching model is one of the frequently observed problems. Yilmaz believes that the problems related to student satisfaction and motivation in the FC teaching model are related to students' e-learning preparation. His research was conducted on 336 undergraduates in the computer I course taught using the FC teaching model. 
$\mathrm{He}$ collected data from three self-reporting tools: the e-learning preparation scale, the satisfaction scale of the learning questionnaire, and motivation strategies [1]. The purpose of Baytiyeh's research is to investigate the effectiveness of the flipped classroom model in teaching and learning and the skills that students can acquire after being exposed to this learning method. A total of 20 students from different majors participated in web design courses. They participated in a survey that included open-ended questions to explore their views on the flipped classroom approach [2]. Kostaris et al. believe that the emerging flipped classroom method has been widely used to strengthen teaching practices in many subject areas and educational levels. However, despite these encouraging studies, the subject area of information and communication technology (ICT) teaching in K-12 education has not been clearly studied [3]. Chi studied the application of flipped classrooms in English subjects in Hong Kong middle schools. He studied the teachers' views on the flipped classroom teaching method; how teachers transfer the flipped classroom experience to the teaching of other classes/subjects. 57 students from two secondary two classes in a three-level middle school and two teachers who taught the two classes participated in the study. He conducted quantitative data analysis [4]. Gough et al. believe that a large amount of evidence on the effectiveness of flipped classrooms can be cited from the higher education literature; however, few studies have been found in flipped classrooms at the K-12 level. He investigated the opinions of K-12 teachers on flipped classrooms, as well as the differences in teachers' perceptions of different grades and teaching content areas [5]. Sergis believes that the mixed learning environment supported by the flipped classroom model (FCM) has been repeatedly studied in both research and practical environments, mainly in terms of their ability to cultivate students' ability to recognize learning outcomes and the overall motivation of the learning process. Therefore, he used the theory of self-determination as a theoretical framework to model the "needs" of these students [6]. Wang believes that how to promote the participation and achievement of flipped classrooms has always been a key research question. His research focuses on exploring how online behavioral participation affects achievements in flipped classrooms. His problem-centric learning process consists of activation, demonstration, application, and integration. He analyzed the learning data collected from ten courses [7].

This research proposes an Internet learning platform based on Tencent QQ communication software and mobile terminals. This learning platform can meet the learning needs of flipped classrooms without spending a lot of hardware and software development investment. This is a relatively ideal Internet learning platform suitable for students to carry out flipped classroom learning. Most of these mobile terminals have functions such as video playback, document reading and editing, wireless network connection, QQ communication, and large-capacity storage. These functions provide support for the smooth implementation of flip class. Students can use mobile terminals to watch anytime, anywhere.

\section{Research Methods}

2.1. Flipped Classroom. The flipped classroom is translated into upside down classroom, upside down learning, upside down classroom, and so on. It is a teaching process that uses video to recreate education: Before class, teachers use information technology to create teaching microvideos that generally do not exceed ten minutes, and students use learning self-service platforms to watch microvideos to learn new knowledge points and watch videos with them. The doubts and the questions in the exercises enter the learning and communication link in the classroom. This stage is the transfer stage of preclass knowledge. Compared with the traditional preparatory stage, students have experienced more in-depth learning; in the classroom, teachers scientifically design teaching activities and organize students to participate, and through teacher-student, student-student exchanges, and collaborations, peer's collaborative exploration and display of their own learning results complete the understanding and mastery of the knowledge in this section. After class, students can continue to improve their knowledge structure based on the learning resources provided by the teacher, and further strengthen the content that they have not fully grasped in the classroom, and finally complete the meaning construction of their own knowledge system. Setting up a discussion link in the classroom can also allow teachers to pay more attention to students with weak foundations and provide individual tutoring to these students to help complete the understanding of knowledge. For students with excellent performance, teachers can also ask more in-depth questions in their groups, which is conducive to the implementation of differentiated teaching, paying attention to each student to fully reflect the student's dominant position [8].

In the class, the teacher divides the students into groups and assigns group cooperative exploration tasks, while the teacher assists and explains the students' confusion and expands some knowledge points appropriately; after class, the students consolidate the new learning content through exercises and correct mistakes by themselves and reflect and summarize what they have learned. Technical support means teachers make guide plans and microvideos before class, upload them to the cloud education platform, and equip students in the experimental class with tablets, and students use the equipped tablets to download and complete the guide plans and watch the preclass microvideos. The students learn at a pace, download self-test questions and learning materials through the Internet, and feedback the answering process to the teacher through the platform. Teachers and students interact with each other before and during the class by logging in to the platform. This interactive process makes the teacher clear about the student's preview, learning and knowledge reserves, and the confusion in the learning process, as a basis for adjusting the classroom teaching progress and designing teaching activities [9].

2.2. Network Communication. Many scholars define the concept of mobile learning including the use of mobile terminals and mobile wireless communication networks. 
Mobile learning needs to be realized through mobile communication equipment and mobile interconnection technology. This is the key to the difference between mobile learning and digital learning. Devices that implement mobile learning should have the main characteristics of portability, mobility, and wireless networking (such as mobile phones, PDAs, and laptops). The various characteristics of mobile terminals are an important guarantee for the effective development of mobile learning and the design and research of mobile learning resources. First of all, the mobility and portability of mobile terminals make learning not affected by time, space, and external environment. It is undoubtedly a very convenient and efficient learning tool. Mobile terminals are interactive, not only can communicate in real time through text messages and calls but also can use a variety of social software to use the network to achieve real-time transmission and sharing of voice, images, files, etc. without incurring any communication costs [10].

Network communication performance is an important guarantee for the smoothness of online courses. Online learning mainly refers to learning in an electronic environment composed of communication technology, microcomputer technology, computer technology, artificial intelligence, network technology, and multimedia technology with the help of network resources. The online learning environment is the guarantee of online learning, which greatly affects the satisfaction of college students with online learning. Environmental factors include learning equipment, communication performance, and learning support [11].

With the increasing formation of the current information society and the continuous intensification of the network process, the development of information fusion technology is facing new issues. The research of information processing methods based on the network communication environment is imminent, which has particularly important theoretical and practical significance. At the same time, the emergence of many new technologies and methods in other fields provides the possibility for the formation of a theoretical system of information fusion based on the network environment, especially the application of artificial intelligence technologies such as engineering fuzzy sets and neural network technology. Information fusion is a complex system engineering. It is very difficult to solve this problem simply by using traditional methods. A more realistic and effective solution is to decompose the complex information fusion problem into a series of subproblems and then adopt different theoretical methods to solve them according to the characteristics of each subproblem, in order to improve and promote the in-depth and development of information fusion theory research [12]. In the process of network communication, set any mapping from the given universe $U, U$ to the closed interval $[0,1]$ :

$$
U \longrightarrow[0,1], u \longrightarrow \mu_{A}(U)
$$

Under normal circumstances, it can be expressed as [13]

$$
A=\{(L,(A(L))) \mid L \in U\} .
$$

If $U$ is a finite set or a countable set, it can be expressed as [14]

$$
A=\frac{\sum_{i=1}^{n} A\left(L_{i}\right)}{L+\alpha\left[\sum_{i=1}^{n} B\left(L_{i}\right) / L-\sum_{i=1}^{n} C\left(L_{i}\right) / L\right]},
$$

or expressed as a vector (called a fuzzy vector) [15]:

$$
A=\left(A\left(L_{1}\right), A\left(L_{2}\right), A\left(L_{3}\right), A\left(L_{4}\right), \cdots, A\left(L_{n}\right)\right) .
$$

The poles transitioned by the reference continuum have the largest relative superiority (relative superiority of superior decision-making) [16]:

$$
G=\left(G_{1}, G_{2}, G_{3}, \cdots, G_{m}\right)^{T} .
$$

Minimum relative superiority degree [17]:

$$
\begin{aligned}
& B=\left(B_{1}, B_{2}, B_{3}, \cdots, B_{m}\right)^{T} \text {, } \\
& G_{M}=\left(\stackrel{\vee}{\mathrm{j}} r_{1}, \stackrel{\vee}{\mathrm{j}} r_{2}, \stackrel{\vee}{\mathrm{j}} r_{3}, \stackrel{\vee}{\mathrm{j}} r_{4} \ldots, \stackrel{\vee}{\mathrm{j}} r_{m}\right)^{T} \quad(j=1,2,3, \cdots, n),
\end{aligned}
$$

$B_{M}=\left(\stackrel{\vee}{\mathrm{j}} T_{1}, \stackrel{\vee}{\mathrm{j}} T_{2}, \stackrel{\vee}{\mathrm{j}} T_{3}, \stackrel{\vee}{\mathrm{j}} T_{4} \ldots, \mathfrak{\mathrm { j }} T_{m}\right)^{T} \quad(j=1,2,3, \cdots, n)$.

The excitation function of the network output node $p$ adopts the fuzzy optimization model [18]:

$$
L=\frac{1}{1+\left[\left(\sum_{i=1}^{n} w L\right)^{-1}-1\right]}(\alpha+L)=\frac{1}{1+\left[Y_{P}^{-1}-1\right]^{2}}(\alpha+L),
$$

where $\alpha$ is the connection weight of the hidden layer node $h$ and the output layer node $p$ and $w$ is the sample number. Suppose the expected output of sample $j$ is $A_{j}$, then its square error is [19]

$$
E=\frac{1}{2 n} \sum_{j=1}^{n} E_{j} \sum_{i=1}^{n}[\chi+A]=\frac{1}{2 n} \sum_{j=1}^{n}[\beta-A] \sum_{i=1}^{n}[\chi+A] .
$$

2.3. Artificial Intelligence Fusion Algorithm. The era of artificial intelligence requires everyone to have a distinct personality and creative thinking. The difference in creativity just reflects the difference between people. For this reason, using the advantages of artificial intelligence, we can pay attention to the individual development of students and the difference in teaching of students, so that every student will not be left behind. Artificial intelligence provides convenience for teachers, allowing teachers to understand the dynamics of information from each student and provide more scientific and accurate personalized guidance. The development of various forms of microclasses, flipped classrooms, and big data analysis methods has given birth to various intelligent 
interactive teaching systems, gradually realizing digital teaching. Preclass intelligent chemical diagnosis and selfstudy supervision and management, real-time interaction and system feedback in class, personalized guidance, and comprehensive evaluation after class are all made more scientific and standardized due to the support of artificial intelligence and big data precision evaluation. The artificial intelligence technology of big data can record students' learning foundation, learning preferences, learning needs, and learning process from multiple angles, presenting every learning dynamic for teachers, parents, and students scientifically and finally forming a personalized test report, referring to the recorded data, and personalized suggestions give an appropriate solution strategy. These real-time feedbacks and evaluations provide intelligent suggestions for teachers to implement precise teaching strategies and effectively improve classroom teaching effects and student learning efficiency.

Explore the complementarity of bilingual recognition, improve the performance of bilingual maximum noun phrase recognition, use bilingual collaborative training to improve the domain adaptability of the recognition algorithm, and incorporate the bilingual maximum noun phrase into the statistical translation model to make the translation more grammatical.

$$
\mathrm{w}=R H \sum_{k=1}^{K} P\left(W \mid o_{k}\right) .
$$

Among them, $K$ represents the number of classifiers participating in the fusion, $w$ represents the category, and $o$ represents the mode to be classified. For the two-way sequence labeling fusion task, the optimal label of position $i$ is [20]

$$
Z_{Y}=B J \max \left(P\left(Z \mid C_{d}\right)+P\left(Z \mid C_{\vec{d}}\right)\right) .
$$

Among them, $d$ and $\vec{d}$ represent forward and reverse, respectively. In the two-way sequence labeling fusion task, there are only 2 classifiers participating in the fusion [21].

$$
\begin{gathered}
E(y)=P(y \mid c)-P(y \mid c), \\
E\left(y_{d}\right)=P\left(y \mid c_{d}\right)-P\left(y \mid c_{d}\right),
\end{gathered}
$$

where $E(y)$ and $E\left(y_{d}\right)$ indicates how certain the classifier in one direction is to choose the current output category instead of the candidate category given by the classifier in the other direction. The larger of the two is the winning mark at position $i[22]$.

$$
\widehat{y}=\mathrm{RH} \max E(y) \text {. }
$$

The introduction of artificial intelligence into English teaching is a general trend. Artificial intelligence is actually the science of using computers to simulate human intelligence. The rapid development of the information age and the development of computer technology affect the process of social development. The application of artificial intelligence algorithms in reality is what people are most concerned about. Artificial intelligence changes human production and life. The method also plays an irreplaceable role in the field of education and teaching. Language, as the basic tool of human communication, is understandably important. In artificial intelligence technology, language processing, machine translation, speech recognition, etc. are inextricably related to human language learning. In the position-based sequence labeling fusion strategy, the optimal sequence labeling result is to label the candidate sequence with the most wins in a single position in the fusion [23].

$$
E(\mathrm{y})=\sum_{i=1}^{n} \beta
$$

The recognition and alignment of bilingual maximum noun phrases can be regarded as a machine learning process. Its task is to automatically recognize and align the boundary of the bilingual maximum noun phrase for the input bilingual sentence under the given definition of the bilingual maximum noun phrase [24].

$$
\mathrm{BMNP}=\left\{\langle M c, M e\rangle \mid w s_{i}, w s_{i+1}, \cdots, w s_{j} ; 0<i<j\right\} .
$$

The accuracy rate is the ratio of the largest noun phrases that the model correctly recognizes and aligns to all the largest noun phrases that are recognized and aligned.

$$
P_{Z}=\frac{Z_{B}}{S_{D}} \times 100 \%,
$$

where $Z_{B}$ is the number of correctly labeled phrases and $S_{D}$ is the total number of recognized phrases. The recall rate is the ratio of the largest number of noun phrases correctly identified and aligned in the largest noun phrase pairs [25].

$$
Z_{H}=\frac{Z_{B}}{D} \times 100 \%
$$

The above two indicators, accuracy rate and recall rate, reflect the performance of different aspects of bilingual maximum noun phrase recognition and alignment. They constrain each other. Therefore, the two must be considered comprehensively and cannot be ignored. For this reason, their harmonic average value $F$ is introduced [26].

$$
F=\frac{\left(\alpha^{2}+1\right) P D}{\alpha^{2} D+P} \times 100 \% .
$$

The emergence and development of information fusion technology is the result of the development and intersection of many disciplines, and it also provides effective information processing technology and methods for the development of many disciplines. As cutting-edge and key technologies, current and future information integrated processing systems and intelligent control systems will use 
information fusion technology to comprehensively process multisource, multimedia, and multiformat information, so as to provide analysis models, domain experts, and decision makers timely, reliable, and efficient information.

2.4. Flipped Classroom Platform. Students use the Internet for online learning and communication, which requires the support of an online learning platform. Generally speaking, this type of online learning platform should have comprehensive teaching service support functions such as registration, login, personal space, teacher information release, student information feedback, course resource links, file transfer sharing, text exchange, online homework, and quality evaluation. The development of this type of online learning platform requires more professional people, and its server establishment, operation, maintenance, etc. also require a certain amount of capital investment. This research proposes an Internet learning platform based on Tencent QQ communication software and mobile terminals. It can meet the learning needs of flipped classrooms without spending a lot of investment in hardware and software development. This is a relatively ideal Internet learning platform suitable for students to carry out flipped classroom learning. The Internet learning platform composed of Tencent QQ communication software and mobile terminals has the following characteristics.

First, the operation is simple. Nowadays, middle school students, most of the students have been able to use computers and mobile phones proficiently, especially using Tencent QQ, able to use mobile phones and computers to post feelings on QQ, communicate with others, download files, watch videos, etc. In addition, QQ groups are also very convenient to use. You can chat in real time. The members of the group can communicate individually or chat with multiple people. The content of the communication can be text, pictures, voice, video, etc.

Second, it has rich functions. Most of these mobile terminals have functions such as video playback, document reading and editing, wireless network connection, QQ communication, and large-capacity storage. These functions provide support for the smooth implementation of flip class.

The video playback function can meet the needs of students to download and watch microvideos. Students can use mobile terminals to watch anytime, anywhere. The document reading and editing function can help students read related learning materials online, including self-study test questions, task lists, and teaching evaluation forms. The wireless network connection function can help students search online materials and download instructional microvideos in the classroom. QQ communication software is a highly popular software that can meet the needs of students and students and between students and teachers. Its QQ group can provide multiperson chat and communication functions. The group owner builds a group on a certain theme and invites relevant people to join the group for communication. In addition, the QQ group has some very important functions, including uploading files in various formats, downloading files, group mailboxes, group forums, group photo albums, and group announcements. Group announcements are convenient for teachers to publish learning tasks and learning plans. Group files can upload and download microvideos, task lists, teaching evaluation forms, and other materials, and students can use the Internet to download relevant materials for learning. Group forums can improve the release of valuable inquiry knowledge questions to students and teachers.

Third, communication is convenient. When students encounter knowledge they do not understand, in traditional classrooms, once students leave school, it is difficult to communicate with teachers and classmates, which is very inconvenient for students. With the support of the Internet learning platform, students can use QQ to communicate with teachers and classmates. This kind of communication is not limited to the limitations of practice and space. As long as both parties are online, both parties can conduct convenient dialogues and exchanges. Even if the communicating party is not online, you can still exchange information by leaving a message.

These characteristics of the Internet learning platform based on Tencent's QQ communication software and mobile terminals make it possible for every student to complete flipped classroom learning through the Internet learning platform in the classroom. This will be very conducive to the rapid promotion and popularization of flipped classrooms and is a new course. Educational reform provides a way. The Internet learning platform based on Tencent QQ communication software and mobile terminals is shown in Figure 1.

2.5. Composition of the Internet Learning Platform. The composition of the Internet learning platform is analyzed in terms of personnel composition and composition steps. Under this platform, the participants in the learning process, students and teachers, are linked to each other through the QQ of the network terminal, and the learning resources are uploaded by the teacher to the group file. For students to download and watch, students use QQ groups to give feedback and discuss difficult problems. This kind of learning network that flexibly chooses the learning time and place according to the individual student's own situation is very efficient and convenient. The network communication learning environment is shown in Figure 2.

From the perspective of personnel composition, the Internet learning platform based on QQ and mobile terminals is composed of students and teachers. In the flipped classroom Internet platform learning, the teacher guides the students' learning and, at the same time, manages the learning order of the students in the QQ group, acts as the manager of the Internet learning platform, and maintains the QQ group. From the perspective of the construction steps, the construction steps of the Internet learning platform are mainly divided into the following steps. First, a QQ group was established. Teachers establish a QQ group according to the teaching purpose and tasks of the flipped classroom. Students apply to join the group and modify the group's business card. Second, regulations to protect the learning environment are formulated. Rules and regulations are the norms that teachers and students in the group abide by, which can ensure the orderly progress of learning. 


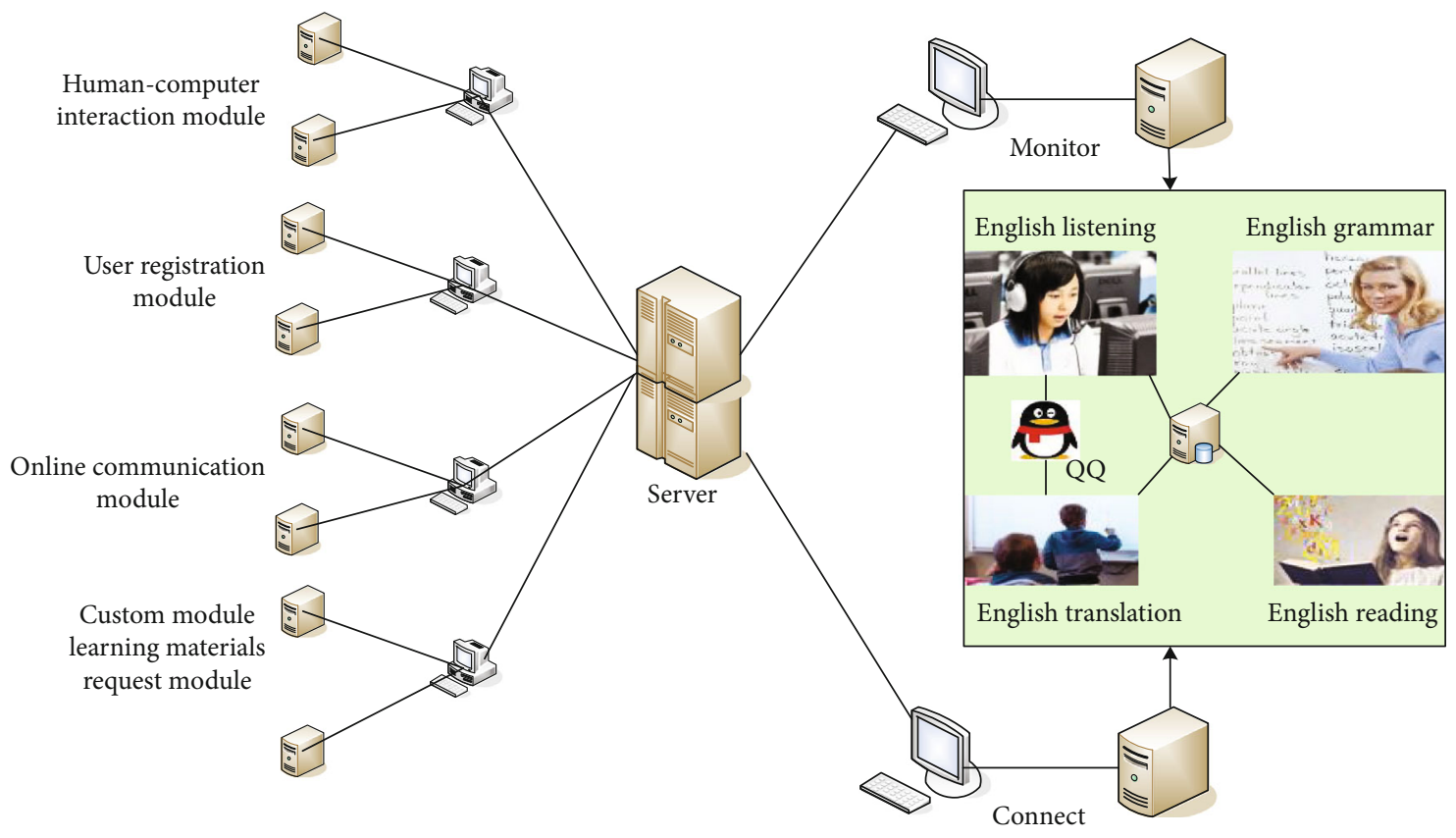

FIGURE 1: Internet learning platform based on Tencent QQ communication software and mobile terminals.

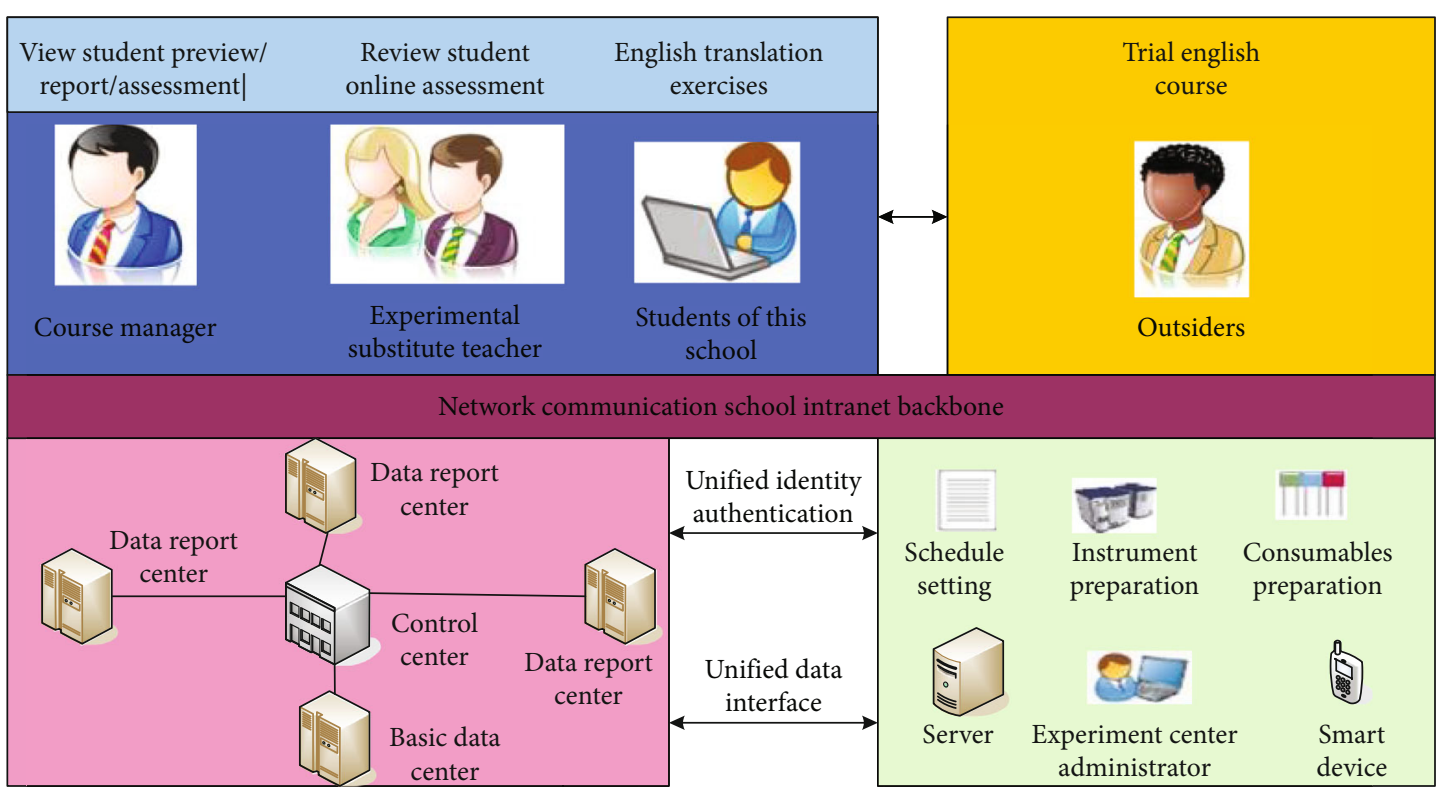

FIGURE 2: Network communication learning environment.

Teachers should keep abreast of the learning dynamics of the students in the group and find and eliminate the content that is not conducive to learning. Third, the learning resources are prepared. Teachers design and produce materials including microvideos, test questions, task lists, and extracurricular knowledge through collective cooperation, or search for suitable teaching materials through network platforms such as basic education resources network and English lesson preparation network. Fourth, a reasonable study plan was made. The teacher publishes the learning tasks and arrangements in the group announcement and informs the students to carry out independent learning according to the teacher's arrangement. Fifth, practical and feasible evaluation feedback channels were established. Teachers summarize and reflect on students' learning progress, learning effects, and problems, so as to establish effective feedback channels and adjust teachers' teaching methods and strategies in time.

2.6. Operation of the Learning Platform. The operation of the Internet learning platform based on QQ and mobile terminals is more flexible and can be used conveniently inside and outside the classroom. The following mainly introduces the operation links of the learning platform. 
TABLE 1: Questionnaire content analysis results.

\begin{tabular}{|c|c|c|}
\hline Dimension & Cronbach's alpha & Number of items \\
\hline $\begin{array}{l}\text { The situation of grammar learning in traditional classrooms and } \\
\text { the enthusiasm of English translation learning }\end{array}$ & 0.825 & 5 \\
\hline $\begin{array}{l}\text { The effect of flipped classroom teaching mode on students' } \\
\text { enthusiasm and initiative in English translation learning }\end{array}$ & 0.824 & 8 \\
\hline $\begin{array}{l}\text { The effect of flipped classroom teaching mode on other learning } \\
\text { aspects of students }\end{array}$ & 0.845 & 4 \\
\hline Satisfaction with the implementation of flipped classroom teaching & 0.824 & 5 \\
\hline Overall scale & 0.873 & 22 \\
\hline
\end{tabular}

First, we have curriculum development and learning resources upload. Teachers develop and produce scientific and reasonable courseware, microvideos, test papers, and other resources based on the teaching standards and the key points of the curriculum and the characteristics of the students. In courseware production, teachers can use online learning resources, learn from others' excellent teaching plans, or collectively prepare lessons. The duration of the microvideo is generally 5-10 minutes, and some enlightening situations are set to guide students to think and ask questions. The production of test papers should be targeted and moderately difficult. At the same time, teachers publish some links and web addresses of network resources for students to refer to in the group announcement to broaden the channels for students to acquire new knowledge.

Second, we have study and test before class. Students use computers, tablets, or mobile phones to log in to the QQ group at home, download the corresponding learning resources, and use the task list as a guide to study new courses in a planned way. After students finish the preclass study, they will test their self-study effects. The Internet learning platform based on QQ and mobile terminals will automatically generate a feedback on test scores. They can think about the problems in the test independently, and they can also seek help from teachers or other students.

Third, we have class discussion and communication. In the group inquiry activities in the classroom, the teacher publishes the inquiry topics in the QQ group. The members of each group are in the group. Under the leadership of the group leader, they use the tablet to log in to the QQ group to obtain the inquiry topics and use the Internet to collect relevant information. Analysis and discussion within the group were conducted, and finally, the conclusions are sorted out and submitted to the platform. After the discussion is completed, the teacher switches the conclusions of each group to the teacher's audio-visual projection equipment, and the group representatives show their findings on the podium. Teachers and students ask questions and discuss the results of each group and vote or score. Finally, the teacher comments on the results of each group, through the process of interaction and communication, to further strengthen students' internalization of knowledge.

Fourth, we have the evaluation and feedback. Students use the teaching evaluation form to score comprehensively according to their performance before and during class activities and fill them out carefully. After filling out, they will feedback to the teacher through the QQ group, and the teacher will give suggestions for improvement to help the students' overall growth and progress.

According to the construction principles and construction basis of teaching evaluation index items, network communication flips classroom teaching functions and teaching elements, and combined with the actual situation, this research is initially constructed from four aspects: student behavior, teacher behavior, media selection and resource development, and teaching content processing network communication flips the evaluation index of classroom teaching.

\section{Results}

Reliability is reliability, which refers to the degree of consistency of results obtained when the same method is used to repeatedly measure the same object. SPSS software was used to analyze the internal consistency and reliability of the questionnaire content. The results of the analysis are shown in Table 1. It can be seen from the reliability test table of the research variables that Cronbach's value of each dimension is greater than 0.7 , and the minimum value is 0.845 , indicating that the reliability of each variable is better: at the same time, the reliability of the total table is 0.873 , which is greater than 0.7. Therefore, it can be considered that the measurement index of the research variable has a high internal consistency reliability, and the data collected by this questionnaire is more credible.

In the questionnaire, 1 point for completely nonconforming representative, 2 points for nonconforming representative, sometimes 3 points for conforming representative, 4 points for conforming representative, and 5 points for fully conforming representative. Table 2 shows the students' attitudes towards English translation learning before the survey experiment.

Impact of the flipped classroom teaching model on other learning aspects of students are investigated, and the results of the survey are shown in Table 3.

The survey when encountering English problems that they do not know is shown in Figure 3. 66\% of the students said they would not search for relevant information on the Internet, and only $34 \%$ of the students said they would search for relevant information on the Internet. This shows that most students have not developed the habit of using information to study. According to interviews with students, 
TABLE 2: Investigating students' attitudes towards English translation learning before the experiment.

\begin{tabular}{|c|c|c|c|c|}
\hline Learning attitude & $N$ & Minimum & Maximum & Mean \\
\hline Cannot keep up with the teacher's lecture speed & 40 & 1.80 & 4 & 3.6 \\
\hline $\begin{array}{l}\text { Explain a lot of grammar knowledge first and then let } \\
\text { the students do the corresponding exercises }\end{array}$ & 40 & 1 & 4 & 3.7 \\
\hline I do not like this traditional grammar teaching model & 40 & 2 & 4 & 3.16 \\
\hline $\begin{array}{l}\text { Do not take the initiative to preview the grammar } \\
\text { content to be learned in advance }\end{array}$ & 40 & 2 & 4 & 3.93 \\
\hline Do not actively answer questions in grammar class & 40 & 1 & 4 & 3.69 \\
\hline
\end{tabular}

TABLE 3: The impact of flipped classroom teaching mode on other learning aspects of students.

\begin{tabular}{|c|c|c|c|c|}
\hline Learning attitude & $N$ & Minimum & Maximum & Mean \\
\hline Helpful for reading and learning & 40 & 2 & 5 & 3.3 \\
\hline Improved writing skills & 40 & 1 & 4 & 3.2 \\
\hline Improved self-learning ability & 40 & 1 & 4 & 3.7 \\
\hline More confident & 40 & 2 & 5 & 3.8 \\
\hline
\end{tabular}

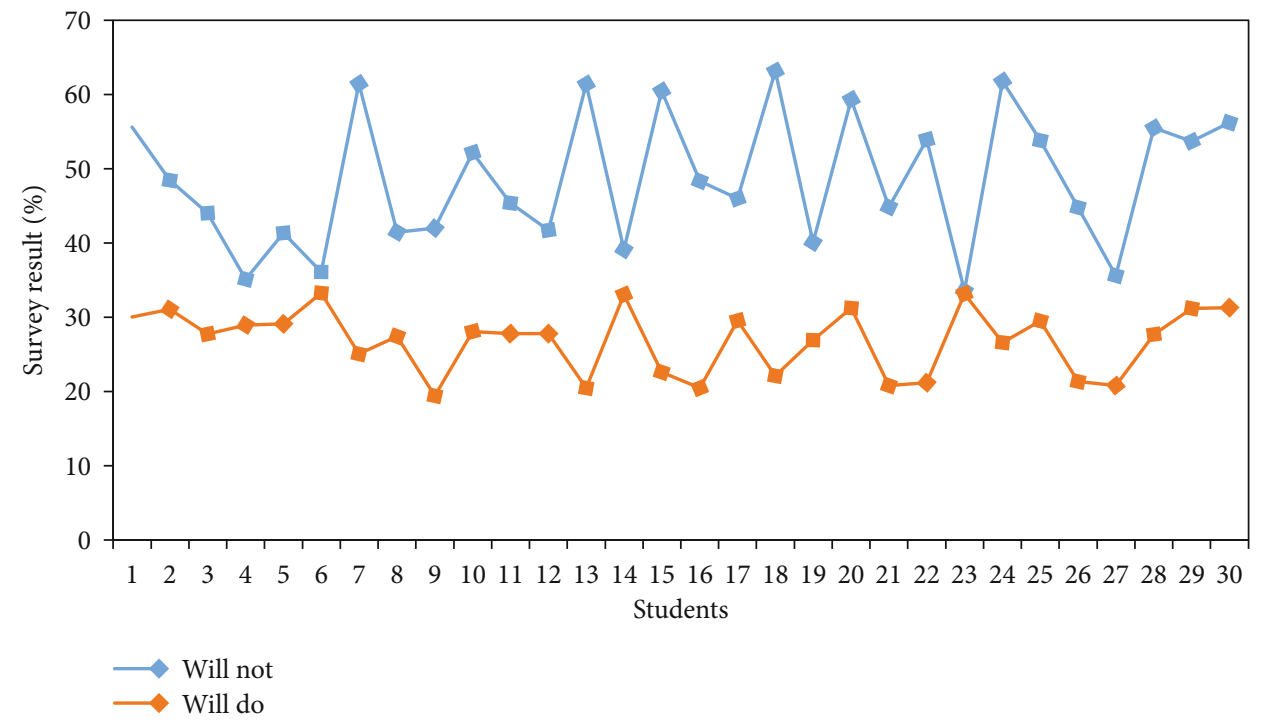

FIGURE 3: Surveys when encountering problems with unfamiliar English.

some students are not very motivated to learn. When they encounter problems, most of them let it go. A small number of students will check the information by themselves or ask the teacher for advice.

$57 \%$ of students think that it is difficult to learn English translation in junior high school, $11 \%$ of students think that learning English translation knowledge in junior high school is relatively general, $20 \%$ of students think it is relatively easy or very easy to learn English translation knowledge in junior high school, and only $12 \%$ of students think It is very difficult to learn English translation in junior high school. This shows that the students' mastery of the method of learning English translation in junior high school is not very good. Some students have not formed good study habits, seldom preview textbooks before class, and will not ask teachers or classmates about knowledge that is not understood in class, and rarely review the knowledge learned in class after class. The attitude of students towards English translation learning is shown in Figure 4.

$70 \%$ of students have not watched English translation teaching videos on the Internet, and only $30 \%$ of students have watched English translation teaching videos on the Internet. According to interviews with students, students watch movies, ball games, TV dramas, and variety shows when they are online, and rarely watch instructional videos on the Internet. The reason is that I do not know that there are English translation teaching videos on the Internet, and I do not know how to get the way to watch the teaching videos. Figure 5 shows the situation of students learning English translation online. 


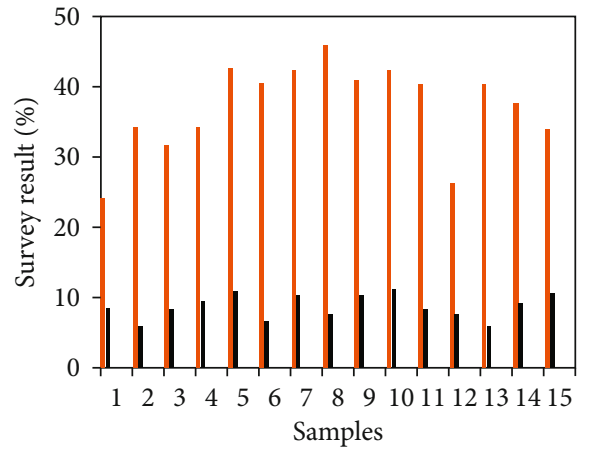

High difficulty

- More general

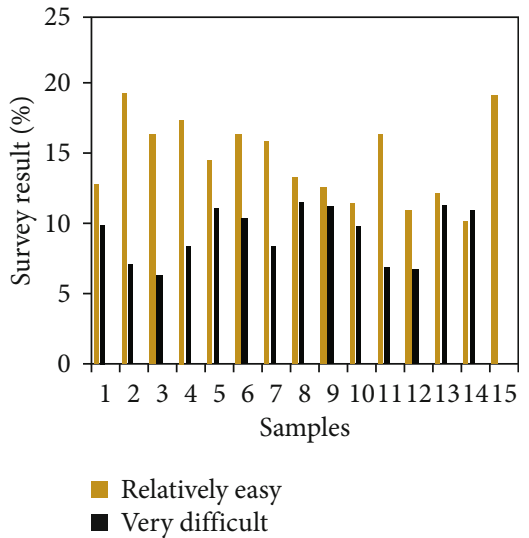

- Very difficult

Figure 4: Students' attitudes towards English translation learning.

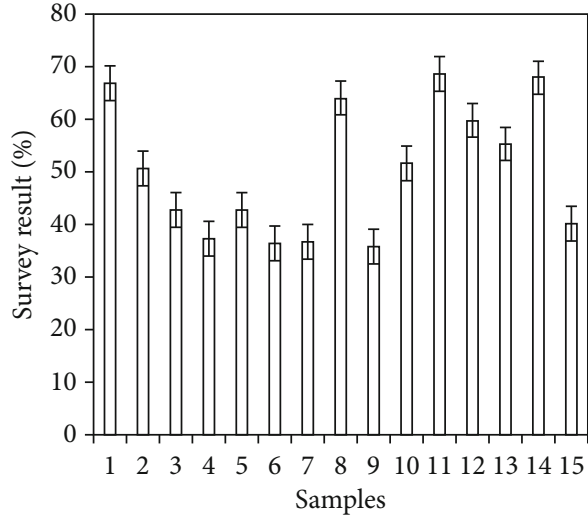

$\square$ Seen

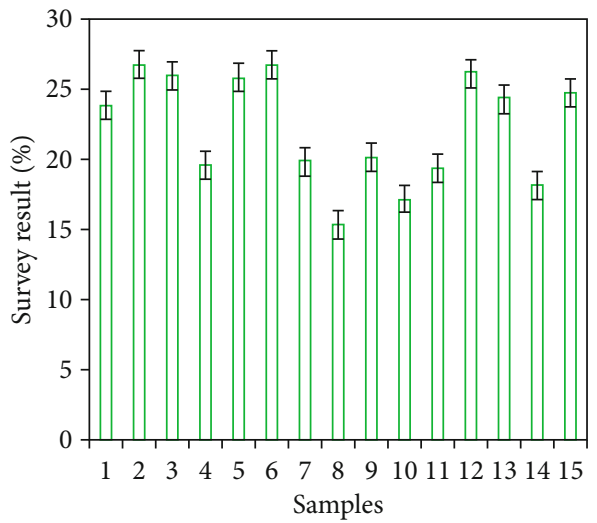

$\square$ Not seen

Figure 5: English translation of students learning online.

$63 \%$ of students are unwilling to actively show their understanding of knowledge to classmates and teachers after they have prepared the English translation knowledge content they want to speak. Only $10 \%$ of students are very willing to take the initiative to participate in this kind of exhibition, and $27 \%$ of students feel average. This shows that most students are shy and dare not speak in front of everyone. This is not conducive to the growth and development of students. A new teaching method is urgently needed to change this unfavorable situation and make students develop more comprehensive and harmonious. The initiative of students to communicate in English is shown in Figure 6.

When learning in the classroom, $47 \%$ of students like to solve the problem by communicating and discussing with classmates, $15 \%$ of students like to communicate with classmates, and $14 \%$ of students have an indifferent attitude. $24 \%$ of students said they did not like this kind of communication and discussion. It shows that most students like a free and relaxed classroom atmosphere. Compared with the teacher's direct answer, students are more willing to communicate and explore on their own. The attitude of students when they are in doubt is shown in Figure 7.
$16 \%$ of students think that it is very helpful to make videos of knowledge points in English and watch them online, $24 \%$ of students think it is helpful, $47 \%$ of students think it may be helpful, and $13 \%$ of students think i hardly helps. This shows that students have not mastered good learning methods, they have no immediate answers to problems encountered in self-study at home, and they will not search for information on the Internet. When the class is in class, teachers seldom leave time to help themselves answer questions, which leads students to find it difficult to learn English. Refined learning on the Internet can help oneself master knowledge and improve grades. Students' views on online video are shown in Figure 8.

Compared with the traditional teaching model, $25 \%$ of students think that they are not used to this learning model, which is not as good as traditional teaching, which increases the burden of learning; $40 \%$ of students hold a neutral attitude and think that flipped classroom or traditional teaching is does not matter; $20 \%$ of students like this way of learning very much, completely accept this way of teaching, think they have gone through the process of inquiry, very catering to their own way of learning, and enjoy the learning process by themselves; $15 \%$ of students are skeptical of flipped 


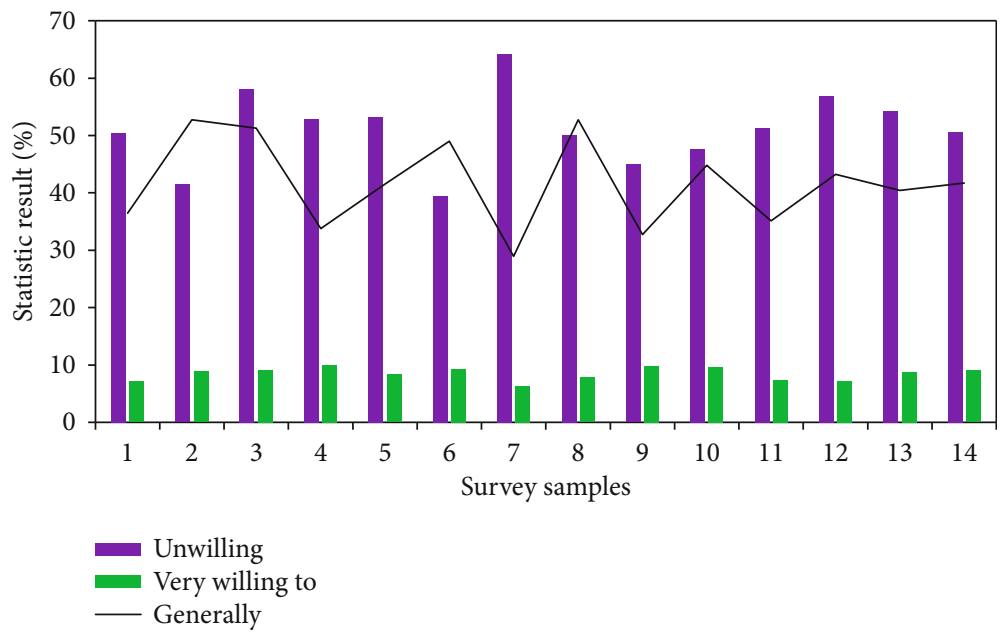

Figure 6: Students' initiative to communicate in English.
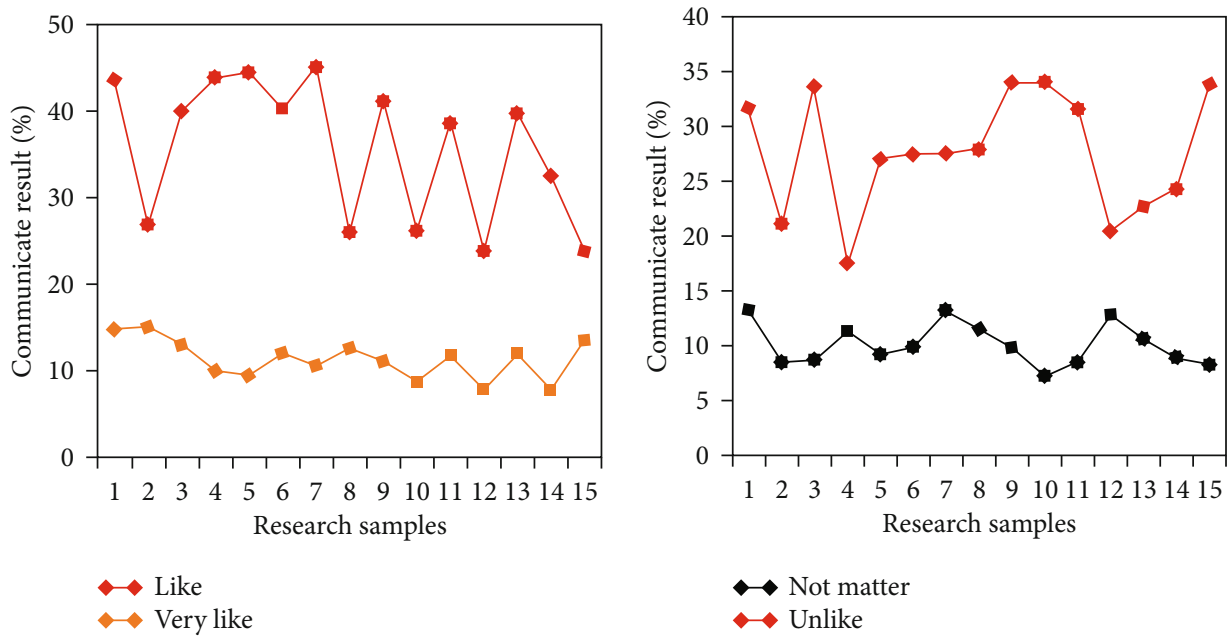

FIgUre 7: Student's attitude when in doubt.

classroom teaching. The student's adaptation to the flipped classroom is shown in Figure 9.

The results of a survey of students' attitudes towards flipped classrooms before the study are shown in Table 4. $55.78 \%$ of students think that the learning effect of flipped classroom is better, $19.8 \%$ of students think that the learning effect of traditional classroom is better, and the other $25.7 \%$ of students think that the effect of the two is similar. More than half of the students believe that flipped classrooms surpass traditional classrooms in learning effects are more obvious.

The overall average score of the dimension of students' satisfaction with the implementation of flipped classroom teaching is 3.75 , which is between sometimes coincidence and coincidence, and is close to the compliance level of 4 points, indicating that students are satisfied with the overall implementation of flipped classroom degree is higher. Table 5 shows the degree of satisfaction of the surveyed students with the implementation of flipped classroom teaching.
After the teaching practice, the same test questions were conducted in the two classes for the same English translation knowledge content, and the test results are shown in Figure 10. In the experimental class, the excellent rate (80 points or more) is $39.7 \%$, the ratio between 70 and 79 points is $34.3 \%$, the ratio between 60 and 69 points is $22.7 \%$, and the failing rate is only $3.3 \%$. In the control class, $28.4 \%$ had a score of 80 or more, $33.3 \%$ had a score of $70-79$, and $30 \%$ had a score of $60-69$, of which $8.3 \%$ had failed.

\section{Discussion}

In traditional classrooms, it is difficult for cooperative learning to truly give full play to the enthusiasm of students to participate in learning and active learning and exploration. The interaction between teachers and students in the classroom can only be formal and lacks real meaning, and collaborative learning under the flipped classroom mode can make up for it. At the same time, by watching the results of other students or groups, they can learn from each other's 

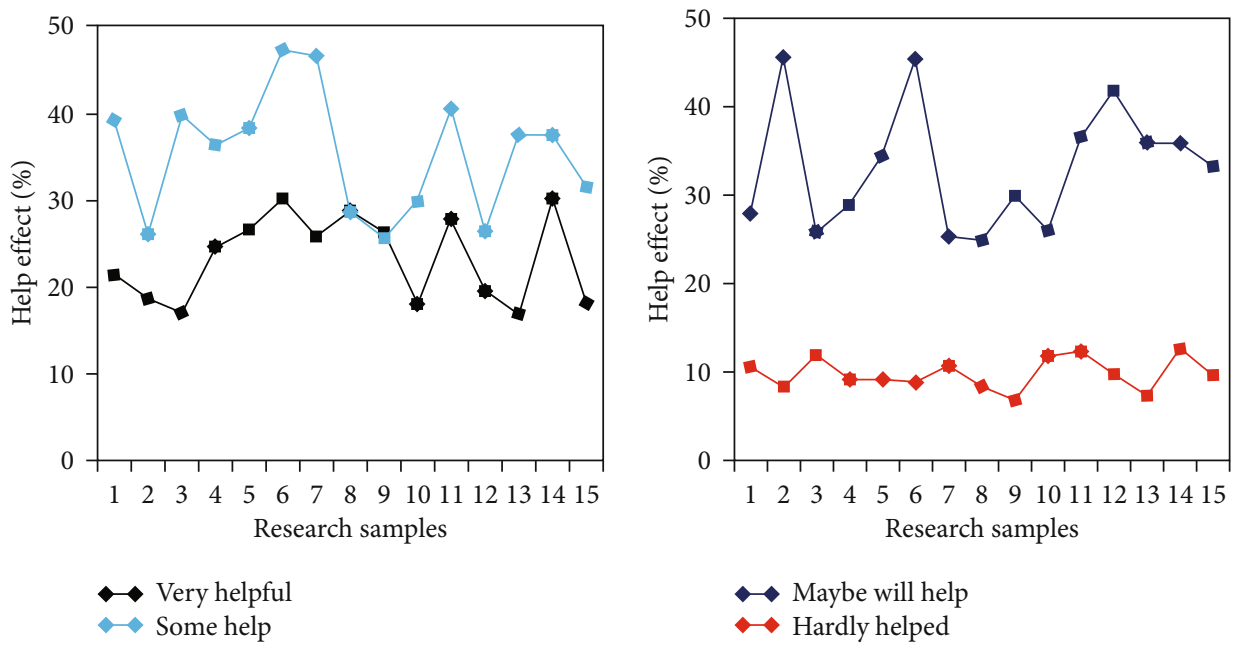

FIgURE 8: Students' views on online video.

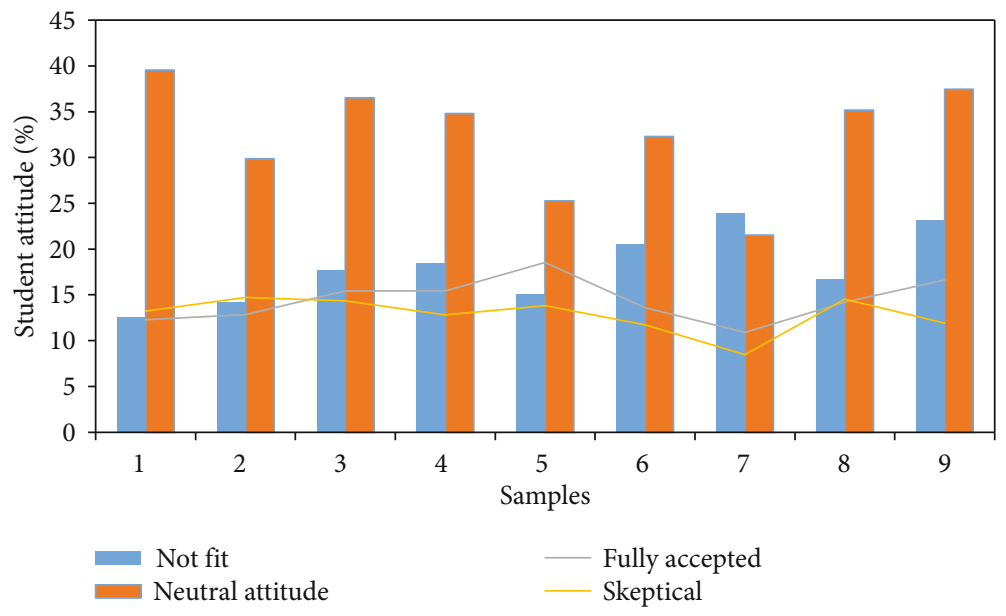

Figure 9: Students' adaptation to the flipped classroom.

strengths and gain a deeper level of knowledge. After the students have finished learning the new knowledge content, timely consolidation exercises can help teachers get real feedback information on whether the students really master the knowledge. Generally speaking, the number of consolidation exercises is five to six, and the difficulty is appropriately higher than that of the self-study effect test. The time for students to solve the problem is controlled at about five minutes. After completing the consolidation exercises, the students began to fill in the teaching evaluation form. Regarding their performance in the preclass self-study stage and the classroom activity stage, evaluate yourself truly and objectively, face corrections for your own shortcomings, and continue to develop and improve on your own strengths. On the other hand, they are willing to take the initiative to try new things, show themselves in front of classmates and teachers, and are eager to get everyone's approval. Generally speaking, junior high school students are a group that is innocent, lively, hardworking, full of vigor, daring to experiment, and pursuing independence. The application of flipped classroom to junior high school
TABLE 4: Results of a survey of students' attitudes towards flipped classrooms.

\begin{tabular}{lccc}
\hline Investigation & Frequency & Percent & Valid percent \\
\hline Flipped classroom mode & 39 & 55.7 & 55.6 \\
Normal classroom mode & 13 & 18.6 & 18.5 \\
Almost & 18 & 25.7 & 25.6 \\
Total & 70 & 100.0 & 100 \\
\hline
\end{tabular}

English teaching is not only conducive to students mastering the basic knowledge but also conducive to more comprehensive development of students.

Artificial intelligence technology makes it possible for teachers to provide students with personalized and customized teaching. The problem of teaching students in accordance with their aptitude has not been well solved for a long time. The problem of too large an educated group is particularly prominent. It is difficult for teachers to carry out personalized teaching, and they cannot provide students with individual learning content, learning activities, learning 
TABLE 5: Students' satisfaction with the implementation of flipped classroom teaching.

\begin{tabular}{|c|c|c|c|c|}
\hline Learning attitude & $N$ & Minimum & Maximum & Mean \\
\hline I would like to attend class & 40 & 1 & 4 & 1.290 \\
\hline Have great difficulties & 40 & 2 & 5 & 1.834 \\
\hline Deepen the understanding of grammar knowledge & 40 & 2 & 5 & 1120 \\
\hline Teaching video is interesting & 40 & 1 & 4 & 1.007 \\
\hline
\end{tabular}

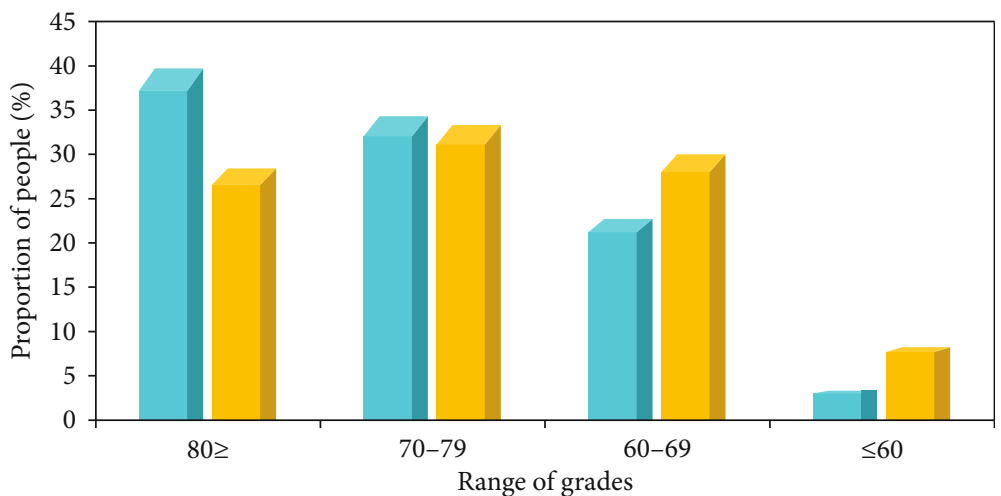

- Experimental class

- Control class

Figure 10: English translation knowledge content test.

methods, and learning evaluation. The arrival of artificial intelligence has brought opportunities for students' personalized customized teaching. The huge system and scientifically recommended teaching resources also provide students with many personalized learning content to suit the development needs of different students' cognitive levels. For this study, the research on flipped teaching is mostly centered on the introduction of the connotation of flipped classrooms, the comparative evaluation of flipped classrooms abroad, and the design of the teaching model of flipped classrooms. However, the practical research on flipped classrooms is especially the use of flipped classrooms in poor areas. There is very little research on the mode and design of teaching practice. This research can enrich and perfect the flipped classroom teaching theory, especially the use of flipped classroom teaching in poverty-stricken areas has certain guiding significance.

Fully reflecting the concept of the new curriculum reform, the new curriculum reform emphasizes the dominant position of students and advocates teacher-student communication, student-student exchanges, and collaboration; differentiated teaching should be adopted for students with different foundations, and innovation in teaching and learning methods should be advocated, and these concepts are also correct. It is advocated by flipped classroom, so the practice of combining flipped classroom with physics classroom also provides an idea for curriculum reform. Through the research, induction and summary of the existing flipped teaching literature, combined with the characteristics of local school, in order to construct an efficient flipped teaching model and then promote the development process of classroom teaching reform, innovate educational concepts to make up for the shortcomings and deficiencies of traditional teaching, exploring the value significance of flipped classrooms for improving students' scientific literacy and improving the quality of education [27].

\section{Conclusion}

This research proposes an Internet learning platform based on Tencent QQ communication software and mobile terminals. This learning platform can meet the learning needs of flipped classrooms without spending a lot of hardware and software development investment. This is a relatively ideal Internet learning platform suitable for students to carry out flipped classroom learning. In traditional classrooms, teachers teach knowledge, students listen carefully, teachers are knowledge imparters and classroom managers, and students are passive recipients of knowledge: in a flipped classroom, throughout the entire teaching process, teachers provide preclass learning materials. Evaluating the learning outcomes in the classroom, proposing extension questions, and guiding students to explore are the role positioning of the instructor and facilitator. Students self-study before class, collaborative discussion in the classroom, and extended learning, they are real active researchers in learning, and the role of teachers and students in teaching has been reversed. How to reasonably use information technology in the daily teaching process and how to use modern information technology to organize students' independent exploration and group cooperative learning, these issues will be considered and explored in the follow-up research and practice. 


\section{Data Availability}

No data were used to support this study.

\section{Conflicts of Interest}

The author states that this article has no conflict of interest.

\section{Acknowledgments}

This work was supported by the Henan Young Backbone Teachers' Training Plan “The Construction and Application of Traditional Chinese Medicine Classics' Translation Corpus"(No. 2018GGJS086) and The Education and Teaching Reform Research and Practice Project of Henan University of Chinese Medicine "The Construction of Multidimensional Medical English Teaching Materials' System Based on Corpus and Demand analysis” (No. 2019JX41).

\section{References}

[1] R. Yilmaz, "Exploring the role of e-learning readiness on student satisfaction and motivation in flipped classroom," Computers in Human Behavior, vol. 70, pp. 251-260, 2017.

[2] H. Baytiyeh, "The flipped classroom model: when technology enhances professional skills," International Journal of Information \& Learning Technology, vol. 34, no. 1, pp. 5162, 2017.

[3] C. Kostaris, S. Stylianos, D. G. Sampson, M. Giannakos, and L. Pelliccione, "Investigating the potential of the flipped classroom model in K-12 ICT teaching and learning: an action research study," Educational Technology \& Society, vol. 20, no. 1, pp. 261-273, 2017.

[4] C. Chi, "An investigation of the use of the 'flipped classroom' pedagogy in secondary English language classrooms," Journal of Information Technology Education Innovations in Practice, vol. 16, no. 1, pp. 1-20, 2017.

[5] E. Gough, D. DeJong, T. Grundmeyer, and M. Baron, "K-12 teacher perceptions regarding the flipped classroom model for teaching and learning," Journal of Educational Technology Systems, vol. 45, no. 3, pp. 390-423, 2017.

[6] S. Sergis, D. G. Sampson, and L. Pelliccione, "Investigating the impact of flipped classroom on students' learning experiences: a self-determination theory approach," Computers in Human Behavior, vol. 78, pp. 368-378, 2018.

[7] F. H. Wang, "An exploration of online behaviour engagement and achievement in flipped classroom supported by learning management system," Computers \& Education, vol. 114, pp. 79-91, 2017.

[8] Ü. Çakıroğlu and M. Öztürk, "Flipped classroom with problem based activities: exploring self-regulated learning in a programming language course," Educational Technology \& Society, vol. 20, no. 1, pp. 337-349, 2017.

[9] P. V. Roehling, L. M. Root Luna, F. J. Richie, and J. J. Shaughnessy, "The benefits, drawbacks, and challenges of using the flipped classroom in an introduction to psychology course," Teaching of Psychology, vol. 44, no. 3, pp. 183-192, 2017.

[10] H. Mohamed and M. Lamia, "Implementing flipped classroom that used an intelligent tutoring system into learning process," Computers \& Education, vol. 124, pp. 62-76, 2018.

[11] Z. Zainuddin, "First-year college students' experiences in the EFL flipped classroom: a case study in Indonesia," International Journal of Instruction, vol. 10, no. 1, pp. 133-150, 2017.

[12] F. S. Sadia, A. F. Manzoor, and E. S. Ather, "Flipped classroom instructional approach in undergraduate medical education," Pakistan Journal of Medical Sciences, vol. 33, no. 6, pp. 14241428, 2017.

[13] C. Lo and K. Hew, "Using "first principles of instruction" to design secondary school mathematics flipped classroom: the findings of two exploratory studies," Educational Technology \& Society, vol. 20, no. 1, pp. 222-236, 2017.

[14] H.-T. Hung, "Design-based research: redesign of an English language course using a flipped classroom approach," TESOL Quarterly, vol. 51, no. 1, pp. 180-192, 2017.

[15] J. Jovanović, D. Gašević, S. Dawson, A. Pardo, and N. Mirriahi, "Learning analytics to unveil learning strategies in a flipped classroom," Internet \& Higher Education, vol. 33, pp. 74-85, 2017.

[16] C. Tang and G. Rundblad, "When safe means 'dangerous': a corpus investigation of risk communication in the media," Applied Linguistics, vol. 38, no. 5, pp. 666-687, 2017.

[17] N. Li, K. V. Pyrkova, and T. V. Ryabova, "Teaching communication skills and decision-making to university students," Eurasia Journal of Mathematics Science \& Technology Education, vol. 13, no. 8, pp. 4715-4723, 2017.

[18] S. Kim, "5G network communication, caching, and computing algorithms based on the two-tier game model," ETRI Journal, vol. 40, no. 1, pp. 61-71, 2018.

[19] T. Prochnow, M. S. Patterson, and L. Hartnell, "Social support, depressive symptoms, and online gaming network communication," Mental Health and Social Inclusion, vol. 24, no. 1, pp. 49-58, 2020.

[20] C. Seguin, T. Ye, and A. Zalesky, "Network communication models improve the behavioral and functional predictive utility of the human structural connectome," Network Neuroscience, vol. 4, no. 4, pp. 980-1006, 2020.

[21] F. Demim, A. Nemra, K. Louadj, M. Hamerlain, and A. Bazoula, "An adaptive SVSF-SLAM algorithm to improve the success and solving the UGVs cooperation problem," Journal of Experimental and Theoretical Artificial Intelligence, vol. 30, no. 3, pp. 389-414, 2018.

[22] X. gao, H. Xue, X. Jiang, and Y. Zhou, "Recognition of somatic cells in bovine milk using fusion feature," International Journal of Pattern Recognition \& Artificial Intelligence, vol. 32, no. 7, pp. 1850021-1850021.19, 2018.

[23] Y. Dai, D. Qiu, Y. Wang, S. Dong, and H. L. Wang, "Research on computer-aided diagnosis of Alzheimer's disease based on heterogeneous medical data fusion," International Journal of Pattern Recognition and Artificial Intelligence, vol. 33, no. 5, pp. 1957001-1957001.17, 2019.

[24] J. Yan, S. Wang, T. Xie, Y. Yang, and J. Wang, "Variational Bayesian learning for background subtraction based on local fusion feature," IET Computer Vision, vol. 10, no. 8, pp. 884893, 2016.

[25] L. Yi, D. Ding, R. Chen, and S. Tao, "Multi-radar fusion technique for high-resolution ISAR imaging in sea-cluttered environment," The Journal of Engineering, vol. 2019, no. 20, pp. 6898-6901, 2019. 
[26] F. Liang, P. Qian, K. H. Su et al., “Abdominal, multi-organ, auto-contouring method for online adaptive magnetic resonance guided radiotherapy: An intelligent, multi-level fusion approach," Artificial Intelligence in Medicine, vol. 90, pp. 3441, 2018.

[27] N. Thai, B. D. Wever, and M. Valcke, "The impact of a flipped classroom design on learning performance in higher education: looking for the best "blend" of lectures and guiding questions with feedback," Computers \& Education, vol. 107, pp. 113-126, 2017. 